\title{
Assessing the Creativity and Its Obstacles based on the Individual Characteristics
}

\author{
Vahid Rouhollahi, Mansoorehossat Rozan, Akhil Mehrotra \\ Department of Physical Education, Banaras Hindu University, Varanasi, India \\ Correspondence concerning this article should be addressed to Vahid Rouhollahi, Department \\ of Physical Education, Banaras Hindu University, Varanasi, U.P., India, Room No.10.E-mail: \\ Email: rouhollahi.vahid@gmail.com
}

Doi:10.5296/jsr.v5i1.5690 URL: http://dx.doi.org/10.5296/jsr.v5i1.5690

\begin{abstract}
This study assessed creativity and its obstacles based on the individual characteristics between sport managers and sport administrators. 108 participants that consist of two equal groups of male and female have completed creativity and creativity obstacle questionnaires. The results of this study indicated that there was no difference between male and female in creativity and factors such as age, educational level and experience level and these factors had no effect on creativity in none of the groups. Other findings of this study indicated differences between male and female in creativity obstacles. We discussed about various aspects of the creativity obstacles in both genders in this investigation.
\end{abstract}

Keywords: Creativity, Obstacles to creativity, Individual characteristics

\section{Introduction}

Creativity has a long history in psychology and behavioral sciences. Creativity is uses of mental abilities for create one thought or new concept and highest level of human learning (Oldham. et al., 1996). The most complicated and highest manifestation of human thought is in his creative thinking. Creativity means creating a new and appropriate design with high value. In other words, creativity is using the mental abilities to create a new idea or concept (Keating, 1980).Creativity is a concept of individual differences which is intended to explain why some people have higher potential to provide new solutions to old problems than others (Emanuel. et al.,2013). creativity can be found in all people but existence of some individual and social factors which cause one cannot show his/her creativity and these factors are creativity obstacles (Kimberly S.Jaussi, 2003).

Guilford's view with respect to creativity is defined on the basis of divergent way of thinking. According to him, divergent way of thinking includes:

- Fluid or flowing: production of ideas in a specific given time, flexibility, creation of varied and unusual ideas and different solutions to a problem.

- Originality: applying new and unique ideas. 
- Development: producing the details and specifying the implications and applications.

- Composition: putting together disparate ideas.

- Analysis: breaking the symbolic structures into their elements, organizing and changing the designs, functions and applications.

- Complexity: having the ability to deal with a number of different and related ideas simultaneously (Guilford, 1982).

The issues of gender differences in abilities and in assessment have also been discussed in the study of creativity (Baer \& McKool, 2009; Kaufman et al., 2010). In fact, the creativity tests are designed to avoid gender biased results (Kim, 2007; Torrance, 1974). A number of studies have shown no gender differences in creativity (Kaufman, 2006; Kogan, 1974). Baer and Kaufman (2008) provided a comprehensive review on the question of gender differences in creativity. In terms of scores on divergent thinking tests, they revealed the following: the evidence does not clearly support gender differences in creativity based on test results; however, to the extent that a case for such gender differences can be made, the available evidence suggests that women and girls tend to score higher on creativity tests than men and boys (Baer \& Kaufman, 2008). Overall, the lack of differences in genders is found in many creativity studies. Baer and Kaufman (2008) then argued that any gender differences in creativity probably stems from an environmental factor. There is evidence of gender differences in creative accomplishment, particularly at the highest level, since there have been more geniuses and distinguished men in the sciences, arts, literature, music, and technical development than women (Eccles, 1985; Eysenck, 1995; Maccoby \& Jacklin, 1974; Reiss, 1999). Gender differences in creative achievement vary considerably according to the field of study, since there are areas such as writing, dance or theatre where women can also be found in the upper ranks (Baer, 1999, 2005; Eysenck, 1995). Some authors have suggested that the cause of masculine superiority in creative achievement is of a biological nature (Eysenck, 1995). Esborn (1950) stated that Physiological, Biological, Social and Psychological obstacle have a very important role in fail of individual to show its creativity. However, it has been suggested that gender differences in creative achievement can be explained by a combination of environmental factors such as: (a) gender differences in access to schooling and resources, since men have historically controlled women's access to many fields and also limited their development; (b) different expectations for and socialization of girls and boys; and (c) men's control of the standards by which an achievement is judged as creative (Baer, 1999, 2005). Furthermore, some authors claim that the myth of the lack of creativity in women is also due to the fact that the creative contributions of women have not been recorded (Reiss, 2002; Simonton, 1992). Simonton considers the creative process to be fundamentally the same among humans, because it emerges directly out of some fundamental features of the human brain as an information-processing system. Yet, there are aspects of the phenomenon that can operate differently depending on gender, ethnicity, socioeconomic level or demographic variables (Simonton, 2002).

Another purpose of the present study was to investigate the obstacles to creativity, with regards to factors such as: gender, age, educational level and experience level. In re-cent 
decades, researchers have been seeking to find the most important creativity obstacles and also overcome them. Brian Tracy (2012) explained six major obstacles to creative thinking that could be preventing people from learning how to improve problem solving skills which are included: lack of direction, fear of failure, fear of criticism, striving for constancy, passive vs. proactive thinking, rationalizing and justifying. Jim Lipcamon (2013) stated four obstacles to creative problem solving such as: constancy, commitment, compression, complacency.

Generally, many factors can cause the lack of creativity in each person that these factors were different in various investigations. In this study, we evaluated six main obstacles to creativity which includes: Lack of self- confidence, Imitation and accompany with traditions, Evaluating based on expectancies, Limited choice, Lack of concentration and Fear from criticism and failure.

This research will help to evaluate and refine techniques developed to cultivate creativity and its obstacles as effectively and efficiently as possible.

\section{Data \& Methodology}

\subsection{Participants}

The participants in the study consisted of 108 graduate or doctoral that included 54 males (Mage $=46.8$ years, $\mathrm{SD}=8.2$ years) and 54 females (Mage $=40.6$ years, $\mathrm{SD}=6.3$ years) which were selected randomly from sport managers and sport administrators who serving in different sport organizations. All participants read and signed an informed consent prior to participation.

\subsection{Instruments}

According to the research objectives, three questionnaires were used as follows:

a. General information questionnaire (individual) required by the study included demographic data and personal characteristics of subjects.

b. Kerman creativity obstacles questionnaire (KCOQ) had been made by the group of psychologists of Kerman University (2006). This questionnaire including 36 questions that each question has 10 choices and each subject can acquire Min +36 and Max +360 points from the whole questions. The KCOQ included 6 subscales: 1) lack of self-confidence 2) imitation and accompany with traditions 3) evaluating based on expectancies 4) limited choice 5) lack of concentration 6) Fear from criticism and failure. The reliability of test was .85 .

c. Creativity questionnaires (RAUDSEPP). This questionnaire was devised by Eugene Raudsepp in 1982. RAUDSEPP test generally fall into a few categories. The most prevalent type is known as 'Task-Oriented' that measure one's fluency and flexibility in generating new ideas. Another category of this test is "Personality-Based" which focuses on personality traits, attitudes, motivations, values, and interests. The latter type of test measures the variables that predispose a person to think creatively. This questionnaire included 50 questions and each question has a Likert scale of five items. 
Each subject can acquire Min -100 and Max +100 points from the whole questions. The reliability of test was .80 .

\subsection{Procedure}

Three questionnaires including general information questionnaire, creativity questionnaire, and creativity obstacles questionnaire as an evaluation tools, distributed between sport managers and sport administrators in different levels of sport society. We asked the participants to answer the questions as they are, not as they think or desire to be. All completed questionnaires were collected after a few days.

\section{Results}

In evaluating gender differences in creativity, we found that, there was no significant differences between creativity scores in male group and female group $\mathrm{t}(106)=.944 ; \mathrm{p}=.348$. The mean of male group was (Mean=45.66; $\mathrm{SD}=16.88$ ) and female group was (Mean=48.70; $\mathrm{SD}=16.56)$.

The results revealed that a weak and negative correlation that was not significant found between age and creativity scores in male group $\mathrm{r}(52)=-.154 ; \mathrm{p}=.268$ and female group $\mathrm{r}$ $(52)=-.018 ; \mathrm{p}=.899$.

The results indicated that there was a weak, negative and not significant correlation between experience levels and creativity scores in male group $\mathrm{r}(52)=-.158 ; \mathrm{p}=.255$, but the correlation was weak, positive and not significant $\mathrm{r}(52)=.185 ; \mathrm{p}=.181$ in female group.

In compared creativity scores between graduate level and doctoral level we found that, there was not significant differences in male group $\mathrm{t}(52)=.967 ; \mathrm{p}=.338$, the mean of doctoral male group was $($ Mean $=43.44 ; \mathrm{SD}=19.18$ ) and graduate male group was (Mean $=47.88 ; \mathrm{SD}=$ 14.33); also no significant difference found between doctoral female group and graduate female group $\mathrm{t}(52)=.712 ; \mathrm{p}=.480$. The mean of doctoral level was $($ Mean $=50.44 ; \mathrm{SD}=17.86)$ and graduate level was $($ Mean $=47.206 ; \mathrm{SD}=15.52)$.

A correlation coefficient was calculated for relationship between participants' age and six obstacles to creativity. There was moderate, positive and significant correlation between participants' age and criticism and failure obstacle in male group $\mathrm{r}(52)=.435 ; \mathrm{p}<0.01$ but not in female group $\mathrm{r}(52)=.068 ; \mathrm{p}=.626$ and also there was moderate, negative and significant correlation between participants' age and limited choice obstacle in male group r(52) = -.379; $\mathrm{p}<0.01$ but not in female group $\mathrm{r}(52)=.052 ; \mathrm{p}=.709$; We couldn't find any significant correlation in other obstacles to creativity such as; self-confidence obstacle in male and female group $\mathrm{r}(52)=.190 ; \mathrm{p}=.169 ; \mathrm{r}(52)=-.128 ; \mathrm{p}=.241$, imitation and accompany with traditions obstacle in male and female group $\mathrm{r}(52)=.09 ; \mathrm{p}=.513 ; \mathrm{r}(52)=.122 ; \mathrm{p}=.379$, evaluating based on expectancies obstacle in male and female group $\mathrm{r}(52)=.239 ; \mathrm{p}=.081$; $\mathrm{r}(52)=-.026 ; \mathrm{p}=.852$, and lack of concentration obstacle in male and female group $\mathrm{r}(52)$ $=.162 ; \mathrm{p}=.241 ; \mathrm{r}(52)=.063 ; \mathrm{p}=-.653$.

Correlation coefficients between males' experience level and six obstacles to creativity were as follows: lack of self- confidence $\mathrm{r}(52)=.100 ; \mathrm{p}=.473$; imitation and accompany with 


\section{Macrothink}

Journal of Sociological Research

ISSN 1948-5468

2014, Vol. 5, No.1

traditions $\mathrm{r}(52)=-.207 ; \mathrm{p}=.133$; evaluating based on expectancies $\mathrm{r}(52)=.042 ; \mathrm{p}=.762$; limited choice $r(52)=-.212 ; \mathrm{p}=.125$; lack of concentration $\mathrm{r}(52)=.084 ; \mathrm{p}=.548$; and fear from criticism and failure $r(52)=-.144 ; \mathrm{p}=.298$.

Correlation coefficients between experience level and six obstacles to creativity in female were as follows: lack of self- confidence $\mathrm{r}(52)=.098 ; \mathrm{p}=.480$; imitation and ac-company with traditions $\mathrm{r}(52)=.187 ; \mathrm{p}=.175$; evaluating based on expectancies $\mathrm{r}(52)=-.216 ; \mathrm{p}=.116$; limited choice $r(52)=-.118 ; p=.396$; lack of concentration $r(52)=-.147 ; p=.288$ and fear from criticism and failure $\mathrm{r}(52)=.017 ; \mathrm{p}=.904$. As results showed , there was no relationship between participants' experience level and six obstacle to creativity in both groups.

Comparison of six creativity obstacles between graduate and doctoral level we found that only significant differences between male graduate level and male doctoral level in limited choice obstacle $\mathrm{t}(52)=2.08 ; \mathrm{p}<0.05$. This obstacles' mean in doctoral level was $(\mathrm{M}=5.81 ; \mathrm{SD}$ $=1.02)$ and in graduate level was $(\mathrm{M}=6.48 ; \mathrm{SD}=1.29)$. Also, there was a significant differences between female graduate level and female doctoral level in fear from criticism and failure $\mathrm{t}(52)=2.248 ; \mathrm{p}<0.05$. This obstacles' mean in doctoral level was (Mean $=6.32 ; \mathrm{SD}$ $=1.64)$ and in graduate level was $(\mathrm{M}=5.31 ; \mathrm{SD}=1.62)$. Other results indicated that, there was no significant difference between graduate level and doctoral level in both groups. The results according to gender appear in table 1 and 2. 
Table1. Educational level difference for creativity obstacles in male group

\begin{tabular}{|c|c|c|c|c|c|c|}
\hline \multirow{2}{*}{ variables } & \multicolumn{2}{|c|}{ Graduate } & \multicolumn{2}{|c|}{ Doctoral } & \multirow[b]{2}{*}{$\mathrm{t}(52)$} & \multirow[b]{2}{*}{$\mathrm{p}$} \\
\hline & M & $\mathrm{SD}$ & M & SD & & \\
\hline Lack of self- confidence & 5.63 & 1.76 & 5.58 & 1.76 & .112 & .911 \\
\hline Imitation and accompany with traditions & 6.86 & 1.08 & 6.95 & 1.44 & .246 & .807 \\
\hline Evaluating based on expectancies & 5.67 & 1.54 & 5.68 & 1.39 & .018 & .985 \\
\hline Limited choice & 6.48 & 1.29 & 5.81 & 1.29 & 2.08 & $.042 *$ \\
\hline Lack of concentration & 5.27 & 1.69 & 5.40 & 1.71 & .280 & .781 \\
\hline Fear from criticism and failure & 5.07 & 1.62 & 4.86 & 1.72 & .446 & .657 \\
\hline
\end{tabular}

$* \mathrm{p}<0.05$ level

Table2. Educational level difference for creativity obstacles in female group

\begin{tabular}{|c|c|c|c|c|c|c|}
\hline \multirow{2}{*}{ variables } & \multicolumn{2}{|c|}{ Graduate } & \multicolumn{2}{|c|}{ Doctoral } & \multirow[b]{2}{*}{$\mathrm{t}(52)$} & \multirow[b]{2}{*}{$\mathrm{p}$} \\
\hline & $\mathrm{M}$ & SD & M & SD & & \\
\hline Lack of self- confidence & 5.59 & 1.62 & 5.29 & 1.72 & .652 & .517 \\
\hline Imitation and accompany with traditions & 6.36 & 1.74 & 5.84 & 1.75 & 1.095 & .279 \\
\hline Evaluating based on expectancies & 5.35 & 1.54 & 5.53 & 1.09 & .500 & .619 \\
\hline Limited choice & 5.25 & 1.67 & 5.27 & 1.50 & .04 & .968 \\
\hline Lack of concentration & 6.33 & 1.72 & 5.67 & 1.70 & 1.41 & .163 \\
\hline Fear from criticism and failure & 5.31 & 1.62 & 6.32 & 1.64 & 2.24 & $.029 *$ \\
\hline
\end{tabular}

$* \mathrm{p}<0.05$ level 


\section{Conclusions}

This investigation examined the creativity and its obstacles with regards to gender, also we studied the effect of factors like; age, experience level and educational level on them. The results indicated that gender differences may not effect on creativity.

On the basis of results of this investigation factors such as; age, experience level and educational level may not have an effect on both genders.

In evaluating relationship between participants' age and six obstacles to creativity, only we found relationship between age and fear from criticism and failure in male group; this result shows that this obstacle may rise with increasing participants' age.

We couldn't find any relationship between experience level and creativity obstacles in both genders but the comparison between educational level (graduate \& doctoral) and obstacles to creativity showed that limited choice obstacle in male and fear from criticism in female were different between graduate level and doctoral level, it means that rate of limited choice obstacle in male graduate level was higher than doctoral level and also fear from criticism and failure in female doctoral level was higher than graduate level, this results indicated the role of gender differences on educational level.

Overall, it can be said for revealing personal creativity, initially we must find creativity obstacle with regard to individual characteristics and finally we can eliminate those obstacles. Also we should remember that personal characteristics must be considered for developing the rate of creativity.

\section{References}

Baer, J. (1999). Gender differences. In M. A. Runco \& S. Pritzker (Eds.). Encyclopedia of creativity (Vol. 1,pp. 753-758). San Diego: Academic Press.

Baer, J. (2005). Gender and creativity. Paper presented at the Annual Meeting of the American Psychological Association, Washington, DC (August).

Baer, J., \& McKool, S. S. (2009). Assessing creativity using the consensual assessment technique. In C. S. Schreiner (Ed.), Handbook of research on assessment technologies, methods, and applications in higher education (pp. 65-77). Hershey, PA: IGI Global.

Baer, J., \& Kaufman, J. C. (2008). Gender differences in creativity. The Journal of Creative Behavior, 42(2), 75-105.

Barron, F., \& Harrington, D. M. (1981). Creativity, intelligence, and personality. Annual Review of Psychology, 32(1), 439-476.

Brian Tracy (2012). 6 Obstacles to Creative Thinking and How to Overcome Them: Develop Problem Solving Skills for Business Success. https://www.briantracy.com/blog/business-success.

Eccles, J. S. (1985). Why doesn't Jane run? Sex differences in educational and occupational patterns. In F. D. Horowitz \& M. O’Brien (Eds.), The gifted and talented: Developmental 
perspectives (pp. 251-300). Washington, DC: American Psychological Association.

Emanuel Jauk, et al. (2013). The relationship between intelligence and creativity: New support for the threshold hypothesis by means of empirical breakpoint detection. Intelligence, $41,212-221$.

Eysenck, H. J. (1995). Genius. The natural history of creativity. Cambridge: Cambridge University Press.

Guilford, J.P., 1982. Cognitive psychology's ambiguities: Some suggested remedies. Psychological Review, 89(1): 48-59.

Jim Lipcamon (2013). Four Obstacles to Creative Problem Solving. http://www.diagnosticimaging.com.

Kaufman, J. C. (2006). Self-reported differences in creativity by ethnicity and gender. Applied Cognitive Psychology, 20(1), 1065-1082.

Kaufman, J. C., Baer, J., Agars, M. D., \& Loomis, D. (2010). Creativity stereotypes and the consensual assessment technique. Creativity Research Journal, 22(2), 200-205.

Keating, D.P. (1980). Four faces of creativity: The continuing plight of the intellectually under served. Gifted Child Quarterly, 24: 56-61.

Kim, K. H. (2007). The two Torrance creativity tests: The Torrance tests of creative thinking and thinking creatively in action and movement. In A. G. Tan (Ed.), Creativity: A handbook for teachers (pp. 117-142). Hackensack, NJ: World Scientific Publishing.

Kimberly S.Jaussi. (2003).Leading for creativity: The role of unconventional leader behavior, the leadership quarterly, 14, 475-498.

Kogan, N. (1974). Creativity and sex differences. The Journal of Creative Behavior, 8(1), $1-14$.

Maccoby, E. E., \& Jacklin, C. N. (1974). The psychology of sex differences. Stanford: Stanford University Press.

Oldham,Greg R. Cummings, Anne. (1996). Employee creativity: Personal and contextual factors at work, Academy of management journal, 39, 57-78.

Raudsepp, Eugene. (1982). How To Create New Ideas for Corporate Profit and Personal Success, Englewood Cliffs, NJ: Prentice Hall.

Reiss, S. M. (1999). Women and creativity. In M. A. Runco \& S. Pritzker (Eds.). Encyclopedia of creativity (Vol. 2, pp. 699-708). San Diego: Academic Press.

Simonton, D. K. (1992). Gender and genius in Japan: Feminine eminence in masculine culture. Sex Roles, 27, 101-119

Simonton, D. K. (1999). Origins of genius: Darwinian per-spectives on creativity. New York: Oxford University Press. 


\section{Macrothink}

Journal of Sociological Research

ISSN 1948-5468 2014, Vol. 5, No.1

Simonton, D. K. (2002). Underrepresented populations in creativity research. Creativity Research Journal, 14, 279-280.

Torrance E. P. (1974). Torrance tests of creative thinking: Norms-technical manual. Bensenville, IL: Scholastic Testing Service. 